\title{
IMPLEMENTASI GERAKAN MASYARAKAT MAGHRIB MENGAJI DALAM UPAYA PEMBINAAN KEAGAMAAN DI DESA BANJAR LOPAK
}

\author{
Handal Pratama Putra \\ Universitas Islam Indonesia, Yogyakarta, Indonesia \\ handalputra29@gmail.com
}

DOI: 10.20885/tarbawi.vol14.iss1.art3

\begin{abstract}
This study aims to see the implementation of the Maghrib Recitation Community Movement (Gerakan Masyarakat Maghrib Mengaji) in its efforts to form a Quranic generation and build morals and protect theirselves from bad influences. This movement emerged as an effort to increase public awareness in revitalizing the tradition of reading the Koran. The researcher has chosen to use a qualitative research approach for this research. This research is located in Kuantan Singingi Regency, namely in a village called Banjar Lopak in Benai sub-district. The researcher used purposive sampling in selecting informants in this study and included three techniques in data collection which included interviews, observation and documentation. Researcher used data collection techniques with triangulation. The study found that religious development through the Maghrib Recitation Community Movement had been carried out well with Quran teaching activities, worship practices and public speaking training. The target of this movement is Muslim families from children to adults, but in practice this movement is only followed by children. The obstacle faced by teachers is that there are a number of children who are difficult to manage in the process of teaching activities. The implementation of the Maghrib Recitation Community Movement in Banjar Lopak Village has been carried out and
\end{abstract}




\section{el-Tarbawj Handal Pratama Putra}

continues to innovate on an ongoing basis. However, this movement needs to evaluate the programs implemented in order to measure the success of these programs.

Keywords: Community Movement, Quran Recitation, Quranic Generation. 


\section{Abstrak}

Penelitian ini bertujuan untuk melihat pelaksanaan Gerakan Masyarakat Maghrib Mengaji dalam usahanya membentuk generasi Qurani dan membangun akhlak serta membentengi diri dari pengaruh buruk. Gerakan ini muncul sebagai usaha untuk meningkatkan kesadaran masyarakat dalam merevitalisasi tradisi membaca Al-Qur'an. Peneliti telah memilih menggunakan pendekatan penelitian kualitatif untuk penelitian ini. Penelitian ini berlokasi di Kabupaten Kuantan Singingi, yaitu di sebuah desa yang bernama Banjar Lopak di kecamatan Benai. Peneliti tersebut menggunaan purposive sampling dalam memilih informan dalam penelitian ini dan meliputi tiga tenik dalam pengambilan data yang meliputi wawancara, observasi dan dokumentasi. Peneliti menggunaan teknik penggumpulan data dengan trianggulasi. Penelitian ini menemukan bahwa pembinaan keagamaan melalui Gerakan Masyarakat Magrib Mengaji sudah terlaksana dengan baik dengan terdapat kegiatan pengajaran Al-Qur'an, Praktik ibadah dan pelatihan public speaking. Sasaran gerakan ini adalah keluarga Muslim dari anak-anak sampai dewasa, namun dalam pelaksanaannya gerakan ini hanya dikuti oleh anak-anak. Kendala yang dihadapi oleh pengajar adalah terdapat sejumlah anak yang sulit diatur dalam proses kegiatan pengajaran. Pelaksanaan Gerakan Masyarakat Magrib Mengaji di Desa Banjar Lopak sudah terlaksana dan terus melakukan inovasi secara berkelanjutan. Namun, gerakan ini perlu mengevaluasi terhadap program-program yang dilaksanaan agar dapat mengukur keberhasilan program-program tersebut.

Kata Kunci: Gerakan Masyarakat, Mengaji Al-Qur'an, Generasi Qurani. 


\section{$e^{I-T a r b a w j ~ H a n d a l ~ P r a t a m a ~ P u t r a ~}$}

\section{Pendahuluan}

Sumber pertama ajaran Islam adalah Al-Qur'an (Ali dan Himmawan, 2019). Al-Qur'an berfungsi sebagai pedoman hidup bagi manusia (Ariadi, 2019). Pengajaran Al-Qur'an yang berkelanjutan akan menjadikan generasi berkulitas yang berpegang teguh pada Al-Qur'an sehingga terhindar dari halhal buruk (Robiansyah, 2018). Saat ini perkembangan zaman sangat pesat sekali, terjadi pergeseran nilai dan tradisi di masyarakat, mulai dari perkotaan sampai di perdesaan. Sehingga nilai dan tradisi pada masyarakat Indonesia umumnya bertolak belakang dengan nilai-nilai ajaran Islam.

Mayoritas penduduk yang ada di negara Indonesia memeluk agama Islam. Tahun 2010 dalam catatan BPS (Badan Pusat Statistik), masyarakat yang memeluk agama Islam lebih dari 87 persen, pemeluk agama Kristen mendekati 7 persen, pemeluk Katolik hampir 3 persen, pemeluk Hindu lebih dari 1,5 persen, pemeluk Budha mendekati 1 persen dan pemeluk Kong $\mathrm{Hu} \mathrm{Cu}$ 0,05 persen (Adona, dkk., 2019). Namun, kebanyakan masyarakat lebih senang menghabiskan waktunya dengan bermain gadget dan bermain game dibandingkan dengan membaca (Rosmawati dkk., 2020), utamanya membaca Al-Qur'an bagi masyarakat Muslim dan kegiatan bermanfaat lainnya. APJII atau Asosiasi Penyelenggara Jasa Internet Indonesia dalam survenya yang dilakukan pada 2017 memukan lebih dari 143 juta orang atau lebih dari 54 persen populasi masyarakat Indonesia adalah pengguna aktif internet. 
Rata-rata dari mereka adalah pada rentan usia antara 13 sampai 18 tahun (IPJII, 2014). Kecenderungan masyarakat Indonesia bermain gadget, menjauhkan dari kegiatan-kegiatan yang positif seperti mengaji dan kegiatan yang lebih bermanfaat.

Oleh karena itu, melihat fenomena adanya kesadaran untuk meningkatkan kembali tradisi membaca A-Qur'an melalui GEMMAR MENGAJI atau dengan sebutan lain Gerakan Masyarakat Magrib Mengaji harapanya dapat membentuk generasi Qur'ani dan membangun akhlak serta membentengi diri dari pengaruh buruk dari penggunaan gadget. Hal ini sudah dikuatkan lagi dengan dicetuskannya Pedoman Gerakan Masyarakat Magrib Mengaji yang ditandatangani oleh Menteri Agama RI, Suryadharma Ali lewat Keputusan Menag nomor 150 tahun 2013. Pencetusan ini sebagai usaha untuk meminimalisir dampak negatif yang ditimbulkan dari program-program pertelevisian dan untuk mengkonter pengaruh negatif globalisasi (Direktorat Penerangan Agama Islam, 2014, 6).

Gerakan mengaji pada waktu salat magrib dianggap efektif menangkal pengaruh negatif dari tayangan negatif dari siaran televisi dan mengurangi intensitas waktu anak dalam penggunaan gadget. Melalui Gerakan Masyarakat Magrib Mengaji diharapkan dapat menjaga nilai-nilai religiusitas masyarakat seperti halnya mengaji di langgar, mushola, atau di masjid sehabis magrib. Di tengah-tengah masih minimnya mengajaran keislaman di madrasah atau sekolah utamanya 


\section{$e^{\text {I-Tarbawj Handal Pratama Putra }}$}

dalam hal mengaji, gerakan ini kemudian memiliki peranan penting. Para orang tua siswa yang melihat bahwa pembelajaran agama utamanya bagaimana bisa mengaji dengan baik tentu akan memilih mengikut sertakan anaknya dalam gerakan tersebut, yaitu mengaji di musholla atau mesjid. Lebih dari itu, Gerakan Masyarakat Magrib Mengaji bukan hanya untuk meningkatkan kemampuan anak atau masyarakat dalam membaca Al-Qur'an, akan tetapi juga untuk meningkatkan pemahaman dalam memahami esensi isi dari AlQur'an (Direktorat Penerangan Agama Islam, 2014, 8). Esensi dari Al-Qur'an inilah yang harapannya bisa mewujudkan perilaku masyarakat yang Qur'ani. Namun begitu, tentu perlu keterlibatan banyak pihak seperti pimpinan majelis taklim, da'i, penyuluh, para guru/ustadz, tokoh masyarakat, para ulama, dan orang tua itu sendiri dalam mensukseskan gerakan tersebut.

Gerakan Masyarakat Magrib Mengaji juga menjadi salah satu proses pembinaan keagamaan masyarakat. Untuk mendapatkan outpun yang baik pembinaan keagamaan perlu proses penyempurnaan melalui usaha dan kegiatan secara berkelanjutan. Masdar Helmy berpendapat bahwa proses pembinaan melingkupi beberapa hal, antara lain kegiatan, tindakan dan usaha dalam memperbaiki kualitas keagamaan baik dalam kegiatan kemasyarakatan, akhlak, kepribadian dan tauhid (Helmy, tt, 31). 
Implementasi Gerakan Masyarakat Magrib Mengaji diharapan dapat memberikan bimbingan dan pembinaan pada anak-anak dalam proses pengenalan huruf Al-Qur'an dan baca tulis Al-Qur'an serta pembinaan keagamaan. Berdasarkan observasi awal yang dilakukan peneliti di Desa Banjar Lopak Kabupaten Kuantan Singingi, kegiatan Gerakan Masyarakat Magrib Mengaji sudah berjalan dimana tidak hanya kegiatan pengajaran membaca Al-Qur'an namun pembinaan Praktik ibadah serta pelatihan public speaking juga diajarkan. Salah satu bentuk implementasi gerakan ini melalui pengajaran AlQur'an. Membaca Al-Qur'an ditekankan agar sesuai dengan tajwid dan kaidah membaca yang benar. Belajar dan mengaji Al-Qur'an merupakan kewajiban seorang muslim, karena AlQur'an sebagai kitab suci orang Islam. Badang LITBANG RI pada tahun 1994 telah mengumpulkan informasi tentang metode-metode dalam pengajaran Al-Qur'an diantaranya adalah metode Baghdadiyyah, metode Al Banjari yang ada di Banjarmasin, metode Iqra' yang dicetuskan di Yogyakarta, metode Qira'ati yang terkenal di Semarang, metode Al-Barqi yang ada di Surabaya, metode Hattaiyyah yang ada di Riau, dan masih banyak lagi metode lainnya yang diterapkan di Indonesia (Ma'mun, 2018, 57).

Kegiatan mengaji di desa Banjar Lopak hanya diajarkan dengan satu metode saja, yaitu menggunakan metode iqro'. Penggunaan metode iqro' sendiri dalam sejarahnya diinisiasi di Yogyakarta oleh H. As'ad Human dimana dalam implementasi 


\section{$e^{\text {I-Tarbawj Handal Pratama Putra }}$}

pengajajrannya langsung dengan latihan membaca bertahap. Metode ini menitik beratkan pada membaca huruf Al-Qur'an dengan lancar sehingga sangat mudah diterapan tanpa penggunaan alat-alat lain dalam pengajarannya. Sistem yang diterapkan biasa dikenal dengan Cara Belajar Santri aktif atau CBSA. Ada empat tahapan dalam proses pembelajaran ini. Pertama, tahapan Ath Thoriqoh Bil Muhaakah dimana seorang pengajar terlebih dahulu memberikan contoh cara membacara dengan benar kemudian siswa mengikutinya. Kedua, tahapan Ath Thoriqoh Bil Musyaafahah dimana seorang siswa mencontoh gerak-gerik bibir (pengucapannya) seorang guru dalam membacanya, demikian seorang guru akan melihat gerak-gerik bibir (pengucapannya) seorang siswa untuk memastikan makhrojul hurufnya bisa benar dan bisa memberikan koreksi apabila terdapat kekeliruan. Ketiga, tahapan Ath Thoriqoh Bil Kalaamish Shoriih dimana seorang pengajar diharapkan bisa komuniatif dan mengucapkannya dengan jelas. Keempat, adalah tahapan Ath Thoriqoh Bis Sual Limaqoo Shidit Ta'liimi dimana seorang mengajar mengevaluasi pemahaman siswa dengan cara memberikan beberapa pertanyaan atau menunjuk bacaan tertentu untuk dibaca oleh siswa (Budiyanto, 1995, 2324).

Dalam penelitian ini, peneliti tertarik mengkaji bagaimana implementasi Gerakan Masyarakat Magrib Mengaji selama ini yang ada di Desa Banjar Lopak Kecamatan Benai Kabupaten Kuantan Singingi. Alasan peneliti mengambil tempat di Desa 
Banjar Lopak karena tradisi Magrib mengaji ini sudah ada sejak puluhan tahun lalu sebelum dikeluarkan keputusan Menteri Agama. Penelitian ini bertujuan untuk menjawab pertanyaan penelitian bagaimana implementasi Gerakan Masyarakat Magrib Mengaji dalam upaya pembinaan keagamaan di Desa Banjar Lopak Kecamatan Benai Kabupaten Kuantan Singingi. Peneliti mendeskripsikan bagaimana Implementasi Gerakan Masyarakat Magrib Mengaji dalam upaya pembinaan keagamaan di desa Banjar Lopak kecamatan Benai kabupaten Kuantan Singingi. Penelitian ini dapat bermanfaat untuk menambah wawasan peneliti serta sumbangsih pemikiran bagi masyarakat pada umumnya, serta memberikan informasi mengenai Gerakan Masyarakat Magrib Mengaji sebagai rujukan sehingga bisa diimplementasikan di tempat lain.

\section{Metode Penelitian}

Peneliti memilih penggunaan pendekatan penelitian kualitatif dalam penelitian ini dan masuk dalam jenis penelitian kualitatif deskriptif. Hasil penelitian ini disajikan dalam bentuk gambaran secara deskriptif tentang bagaimana implementasi Gerakan Masyarakat Magrib Mengaji dalam upayanya membina kemampuan mengaji atau kemampuan agama lain yang ada di Kuantan Singingi, tepatnya di desa Banjar Lopak, kecamatan Benai. Secara spesifik lokasi penelitian ini ada di surau Nurul Iman. Surau adalah tempat mengaji yang biasa 


\section{$e^{I-T a r b a w j ~ H a n d a l ~ P r a t a m a ~ P u t r a ~}$}

dikenal dengan mushalla atau langgar. Alasan peneliti memilih surau Nurul Iman tersebut karena tradisi Magrib mengaji sudah lama dilakukan sejak puluhan tahun lalu dan terus melakukan inovasi dalam perkembangannya. Informan dari penelitian ini adalah guru ngaji dan tokoh agama yang ada surau Nurul Iman. Dipilih informan tersebut karena mereka yang menjalankan dan mengelola pelaksanaan gerakan Magrib mengaji di beberapa surau di Desa Banjar Lopak.

Peneliti memilih penggunaan purposive sampling dalam menentukan informan yang terdiri dari guru ngaji dan tokoh agama. Maksud dari purposive sampling adalah dimana informan yang dipilih berdasarkan pertimbangan tertentu atau masuk dalam kriteria (Rosdianto dan Murdani, 2017). Setidaknya para informan yang dipilih memang tepat dan dan mengetahui kondisi di lapangan atau terlibat dalam Gerakan Masyarakat Magrib Mengaji. Secara garis besar ada 3 teknik pengambilan data, yang secara berurutan meliputi observasi, dokumentasi dan wawancara. Peneliti memastikan keabsahan data dengan penggunaan trianggulasi yaitu menggunakan sumber data yang ada. Trianggulasi sendiri sebagai teknik untuk mengevaluasi keabsahan temuan penelitian (Bachri, 2010). Peneliti menggunakan model Miles dan Huberman dalam menganalisi data dengan tahapan pertama reduksi data, kedua penyajian data, dan yang terakhir verifikasi atau penarikan kesimpulan (Miles dan Huberman, 1984). 


\section{Hasil dan Pembahasan}

Kementerian Agama pada tahun 2014 menginisiasi Gerakan Masyarakat Magrib Mengaji dimana sejalan dengan visi "Terwujudnya Kabupaten Kuantan Singingi yang Unggul, Sejahtera, dan Agamis di Provinsi Riau Tahun 2021" yang dibuat oleh pemerintah Kabupaten Kuantan Singingi (Yulianti, 2019). Demi tercapainya kabupaten yang masyarakatnya agamis. Agamis yaitu orang-orang taat dalam menjalankan ajaran agamanya. Khususnya di Desa Banjar Lopak terdapat 1 mesjid dan 3 buah surau. Pada penelitian ini difokuskan di Surau Nurul Iman Desa Banjar Lopak. Sasaran gerakan Magrib mengaji menurut buku pedoman Gerakan Masyarakat Magrib Mengaji yang diterbitkan Kementerian Agama RI yaitu remaja termasuk mahasiswa dan pelajar, pengelola lembaga keislaman seperti majelis taklim atau organisasi masyarakat Islam, pengurus surau atau langgar atau mosholla dan mesjid, dan keluarga muslim itu sendiri. Anak-anak tersebut adalah yang duduk di bangku sekolah mulai dari TK, SD dan SMP. Saat ini anak-anak yang mengaji di surau Nurul Iman berjumlah 35 anak. Anak tidak diajarkan mengaji Al-Qur'an saja, tetapi juga mengajarkan bacaan salat, gerakan shalat yang benar sesuai ajaran Nabi Muhammad, doa-doa pendek, doa setelah shalat wajib, cara menjadi muazin, diajarkan menjadi imam shalat serta pelatihan pembawa acara atau dikenal MC dan diajarkan pula berpidato agama. 


\section{$e^{\text {I-Tarbawj Handal Pratama Putra }}$}

Dalam pelaksanaannya Gerakan Masyarakat Magrib Mengaji di Surau Nurul Iman dibagi tiga kegiatan yaitu; pengajaran Al-Qur'an, praktik ibadah dan pelatihan public speaking. Pertama, pengajaran Al-Qur'an diajarkan dengan metode Iqro'. Metode Iqro' yaitu pengenalan huruf hijaiyah secara bertahap sehingga lancar membaca Al-Qur'an. Pengajaran dilakukan berkelompok secara melingkar atau halaqah. Anak-anak dibagi menjadi beberapa kelompok empat sesuai tingkatan dalam Iqra' dan satunya adalah kelompok yang sudah pandai membaca Al-Qur'an. Setiap kelompok diajar satu orang guru ngaji, setiap anak disuruh membaca bacaan Iqra' dihadapan guru ngaji kemudian sang guru membenarkan dan menilai bacaan anak tersebut. Jika lancar dalam membaca, maka akan dilanjutkan ke halaman berikutnya dan jika tidak lancar maka besoknya mengulang di halaman yang sama. Anak yang lain yang menunggu giliran untuk membaca dihadapan guru diminta untuk bersiap dan mengulang-ulang agar bacaannya lancar dan untuk kelompok membaca Al-Qur'an, diajarkan seni membaca Al-Qur'an dengan seni tilawah. Anak-anak terlebih dahulu diminta menunaikan shalat Magrib dirumah masing-masing atau berjamaah di masjid. Setelah menunaikkan shalat magrib, anakanak diantar orang tuanya ke surau untuk mengaji. Adapun sebelum mengaji, kegiatannya adalah membaca bacaan dalam shalat. Tujuannya agar anak-anak lancar melafazkan bacaan didalam shalatnya. Kegiatan pengajaran mengaji pada hari 
selasa, rabu, jumat mulai dari setelah shalat Magrib sampai menjelang shalat isya yaitu pukul 18.45 sampai 19.30. Hal ini sesuai dengan hasil observasi peneliti ketika datang ke surau Nurul Iman, anak-anak bersemangat dalam belajar mengaji dan anak-anak melingkar dengan rapi ketika proses pengajaran berlangsung namun ada juga terlihat sedikit anak yang mainmain ketika mengaji.

Kedua, Praktik Ibadah. Dalam agama Islam, shalat merupakan ibadah wajib dan jika ditinggalkan mendapat dosa. Di hari akhir atau kiama, amal yang paling pertama dihisap atau ditanya adalah praktik solat lima waktu dalam sehari-hari. Seorang Muslim yang masuk kategori berakal dan sudah baligh dikenakan kewajiban untuk melaksanakan solat lima kali sehari. Maka dari itu, seorang muslim butuh dilatih dan dibiasakan sejak usia dini (Somad, 2018, 17). Latihan salat berjamaah diajarkan dan Praktik setiap hari Kamis. Anak-anak pun dibagi tugas ada yang menjadi muazin, iman shalat dan pembaca doa setelah shalat. Yang menjadi muazin, imam dan pembaca doa adalah anak laki-laki, sedangkan anak perempuan berlatih menjadi makmum. Dengan diajarkannya bacaan dan gerakan shalat kepada anak, kelak anak ketika dewasa dapat menerapkan dalam kehidupan sehari karena shalat merupakan kewajiban seorang muslim (Rofiqoh, 2020). Hal ini juga disampaikan oleh tokoh agama setempat sekaligus guru ngaji di tempat tersebut, Awermun mengatakan bahwa dulunya di surau tersebut hanya proses mengaji saja, namun 


\section{$e^{\text {I-Tarbawj Handal Pratama Putra }}$}

kita berinovasi mengadakan Praktik ibadah ini sebagai proses latihan agar anak-anak selalu ingat shalat dimanapun ia berapa nanti nya ketika dewasa.

Ketiga, pelatihan public speaking. Selain belajar mengaji dan praktik ibadah, pembelajaran lain seperti pelatihan public speaking dianggap menunjang kemampuan anak untuk kedepannya terutama ketika berhadapan dengan orang banyak. Anak-anak diajarkan agar bisa menjadi master of ceremony (MC) agar ketika ada acara dimasyarakat anak-anak ini mampu tampil didepan umum. Selain pelatihan menjadi pembawa acara anak-anak juga dilatih pidato agama agar nanti bisa menjadi seorang da'i atau pendakwah. Kegiatan ini dilaksanakan hari senin dan kamis setelah Praktik ibadah. Peneliti melihat langsung pelatihan pembawa acara dan pidato agama di surau tersebut, dilatih oleh Awermun selaku tokoh agama setempat. Anak-anak yang dilatih diminta untuk tampil dibeberapa acara keagamaan di Desa Banjar Lopak. Seperti kegiatan memperingati Isra' Mi'raj Nabi Muhammad pda bulan Rajab, beberapa anak-anak ada yang ditugaskan menjadi pembawa acara, dan mengisi tilawah Al-Qur'an serta tampil pidato berantai yang beranggotakan tiga anak. Dilibatkannya anak-anak pada acara keagamaan dapat melatih mental mereka untuk lebih berani tampil dan aktif di depan masyarakat umum serta bisa membuat orang tuanya bangga.

Tiga kegiatan tersebut dilaksanakan di surau Nurul Iman Desa Banjar Lopak sebagai pembinaan keagamaan. Kegiatan 
tersebut dilakukan terus-menerus dan melakuan inovasi sehingga menjadikan anak-anak pandai mengaji, pandai beribdah dan mampu tampil dihadapan umum. Walaupun dalam pelaksanaannya terjadi beberapa kendala, salah satunya adalah terdapat sedikit anak yang susah diatur dan menuruti perkataan guru ngaji. Namun guru ngaji tidak kehabisan akal sehingga tidak mengganggu anak-anak yang lain. Kendala ini disampaikan oleh Awermun selaku guru ngaji. Peneliti juga melihat evaluasi gerakan Magrib mengaji jarang dilakukan.

Ada beberapa indikator yang dapat diukur untuk melihat keberhasilan Gerakan Masyarakat Magrib Mengaji. Beberapa indikatornya antara lain; Pertama, semakin tingginya kegemaran dan minat masyarakat atau anak-anak untuk beribadah di surat atu langgar, musholla, atau mesjid; Kedua, efektifnya fungsi mesjid sebagai pusat pembinaan kegiatan beribadah umat Islam dalam hal pembinaan akhlak, ketakwaan, dan keimanan; Ketiga, tingginya kemampuan anaanak dalam membaca dan menulis Al-Qur'an; Keempat turunnya konflik sosial di kalangan masyarakat utamanya orang dewasa atau remaja seperti dalam aksi premanisme atau tindakan kekerasan lain (Direktorat Penerangan Agama Islam, 2014, 18). Dari beberapa indikator keberhasilan tersebut, Gerakan Masyarakat Magrib Mengaji dalam upaya pembinaan keagamaan di Desa Banjar Lopak dapat dikatakan berhasil. Karena dilihat dari masyarakatnya yang gemar dan rajin shalat berjamaah ke masjid, berkembangnya masjid dan surau sebagai 


\section{$e^{\text {I-Tarbawj Handal Pratama Putra }}$}

pusat pembinaan keagamaan, meningkatnya jumlah anak-anak yang pandai mengaji, serta jarang terjadi konflik sosial di desa tersebut pada beberapa tahun terakhir ini.

\section{Kesimpulan}

Gerakan Masyarakat Magrib Mengaji dalam pembinaan keagamaan di Desa Banjar Lopak telah berhasil dilaksanakan dengan baik dengan melihat empat indikator yang ada. Pertama, semakin tingginya kegemaran dan minat masyarakat atau anak-anak untuk beribadah; Kedua, efektifnya fungsi mesjid sebagai pusat pembinaan kegiatan beribadah umat Islam; Ketiga, tingginya kemampuan ana-anak dalam membaca dan menulis Al-Qur'an; Keempat turunnya konflik sosial di kalangan masyarakat. Secara garis besar, ada tiga kegiatan yang dilaksanakan oleh gerakan ini, yaitu: Pertama, pengajaran AlQur'an; Kedua, praktik ibadah; dan Ketiga, pelatihan public speaking. Namun dalam pelaksanaannya terdapat beberapa kendala yaitu ada sejumlah anak yang susah diatur dalam proses pembelajaran. Kemudian evaluasi dari kegiatan di surau terlihat jarang dilakukan. Padahal evaluasi pada kegiatan sangat diperlukan untuk mengetahui efektifitas pelaksanan kegiatan atau program yang dilakukan oleh Gerakan Masyarakat Magrib Mengaji. Penelitian ini diharapkan mampu menjadi rujukan dalam membuat inovasi dalam pelaksanaakan Gerakan Masyarakat Magrib Mengaji di surau Nurul Iman atau 
Implementasi Gerakan Masyarakat Maghrib Mengaji... el-Tarbawj

surau lain yang menyelenggarakan gerakan yang sama. Surau Nurul Ilmu beserta stakeholder yang ada diharapkan ke deapannya terus melakukan inovasi dalam pelaksanaan kegiatan dan melakukan evaluasi agar bisa memperbaiki kekurangan-kekurangan yang ada. 


\section{$e^{\text {I-Tarbawj Handal Pratama Putra }}$}

\section{Daftar Pustaka}

Adona, F., Yusnani, Y. and Sukatik, S., 2019. Padang Halal Tourism: Studi Kasus Terhadap City Branding Pada Pusat Perdagangan Kota Padang. Jurnal Ilmiah Poli Bisnis, pp.143-153.

Ali, M. and Himmawan, D., 2019. The role of hadis as religion doctrine resource, evidence proof of hadis and hadis function to Al-Qur'an (peran hadits sebagai sumber ajaran agama, dalil-dalil kehujjahan hadits dan fungsi hadits terhadap Al-Qur'an). Risâlah, Jurnal Pendidikan dan Studi Islam, 5(1, March), pp.125-132.

APJII, P., 2014. Asosiasi Penyelenggara Jasa Internet Indonesia. Jakarta: APJII.

Ariadi, P., 2019. Kesehatan Mental dalam Perspektif Islam. Syifa'MEDIKA: Jurnal Kedokteran dan Kesehatan, 3(2), pp.118-127.

Bachri, B.S., 2010. Meyakinkan validitas data melalui triangulasi pada penelitian kualitatif. jurnal teknologi pendidikan, 10(1), pp.46-62.

Budiyanto. 1995. Prinsip-prinsip Metodologi Buku IQRO'. Yogyakarta: Team Tadarus "AMM".

Direktorat Penerangan Agama Islam. Pedoman Gerakan Masyarakat Magrib Mengaj. (Jakarta: Kemenag RI, 2014) hal. 6.

Helmy, Masdar. tt. Peranan Dakwah dalam Pembinaan Umat, (Semarang: Dies Natalies, IAIN Walisongo Semarang. 
Ma'mun, Muhammad Aman. 2018. Kajian Pembelajaran Baca Tulis Al-Qur"an, Annaba: Jurnal Pendidikan Islam Volume 4 No. 1.

Miles, M.B. and Huberman, A.M., 1984. Drawing valid meaning from qualitative data: Toward a shared craft. Educational researcher, 13(5), pp.20-30.

Robiansyah, F., 2018, December. Membentuk Generasi Qurani Melalui Program Tahfidz Al-Quran di SDS Peradaban Serang. In Seminar Nasional Pendidikan Dasar (Vol. 3, No. 1, pp. 143-155).

Rofiqoh, A., 2020. Shalat dan Kesehatan Jasmani. Spiritualita, 4(1), pp.65-76.

Rosdianto, H. and Murdani, E., 2017. The implementation of POE (Predict Observe Explain) model to improve student's concept understanding on Newton's law. Jurnal Pendidikan Fisika, 6(1), pp.55-57.

Rosmayati, S., Maulana, A. and Rochman, B.A., 2020. Pengaruh Tradisi Membaca Al-Qur'an Terhadap Prestasi Belajar Siswa di MA Al-Hidayah. Asyahid Journal of Islamic and Quranic Studies (AJIQS), 2(2).

Somad, Abdul. 2018. 99 Tanya Jawab Seputar Shalat. Cetakan IX. Pekanbaru: Tafaqquh Media.

Yulianti, W., 2019. Analisis Transparansi dalam Pengelolaan Anggaran Pendapatan dan Belanja Desa di Desa Telu Beringin Kecamatan Gunung Toar Kabupaten Singingi (Doctoral dissertation, Universitas Islam Negeri Sultan Syarif Kasim Riau). 
el-Tarbawj Handal Pratama Putra

66 Jurnal eL-Tarbawi

Ifolume 14 No.1, 2021 